\title{
Psoriasiform Dermatitis
}

National Cancer Institute

\section{Source}

National Cancer Institute. Psoriasiform Dermatitis. NCI Thesaurus. Code C27724.

A chronic, sporadic, acquired pruritic non-infectious skin condition characterized by one or more well defined inflamed (pink or red) patches or plaques of varying size. 